\title{
Serum uric acid is associated with coronary artery calcification in early chronic kidney disease: a cross-sectional study
}

\author{
Miyeun Han ${ }^{1}$, Hyunsuk Kim², Hyo Jin Kim³ ${ }^{3}$ Eunjeong Kang ${ }^{4}$, Yong-Soo Kim ${ }^{5}$, Kyu Hun Choi ${ }^{6}$, Soo Wan Kim \\ Curie $\mathrm{Ahn}^{8}$ and Kook-Hwan $\mathrm{Oh}^{8^{*}}$
}

\begin{abstract}
Background: Although uric acid (UA) is regarded as a risk factor for cardiovascular disease, whether UA is an independent risk factor contributing to coronary artery calcification in chronic kidney disease (CKD) is not well known. We evaluated whether UA level is associated with coronary artery calcium (CAC) score in a predialysis CKD cohort.

Methods: A total of 1,350 subjects who underwent coronary computed tomography as part of the KoreaN Cohort Study for Outcome in Patients With Chronic Kidney Disease were analysed. We conducted a logistic regression analysis to evaluate the association between UA and the presence of CAC.

Results: CAC was detected in 705 (52.2\%) patients, and the level of UA was significantly higher in CAC >0 patients. UA showed a positive relationship with CAC $>0$ in age- and sex-adjusted logistic regression analysis (Odds ratio (OR) 1.11, $95 \%$ confidence interval $(C I) 1.04-1.19, P=0.003)$. However, UA showed no association with $C A C>0$ in multivariate analysis. Further analysis showed that UA showed a positive association with CAC $>0$ only in estimated glomerual filtration rate (eGFR) $>60 \mathrm{ml} / \mathrm{min} / 1.73 \mathrm{~m}^{2}$ (OR 1.23, $\left.95 \% \mathrm{Cl} 1.02-1.49, P=0.036\right)$ but not in eGFR 30-59 $\mathrm{ml} / \mathrm{min} / 1.73 \mathrm{~m}^{2}$ (OR 0.92, $\left.95 \% \mathrm{Cl} 0.78-1.08, P=0.309\right)$ or $<30 \mathrm{ml} / \mathrm{min} / 1.73 \mathrm{~m}^{2}(\mathrm{OR} 0.92,95 \% \mathrm{Cl} 0.79-1.08, P=$ 0.426).
\end{abstract}

Conclusions: UA level was significantly associated with CAC in early CKD, but not in advanced CKD.

Keywords: Uric acid, Chronic kidney disease, Coronary artery calcification, Coronary computed tomography

\section{Background}

Cardiovascular disease (CVD) is the leading cause of morbidity and mortality in patients with chronic kidney disease (CKD), accounting for more than half of the deaths [1]. Patients with CKD have traditional risk factors for CVD, such as hypertension, diabetes, dyslipidemia, and elderly. In addition, CKD-related risk factors

\footnotetext{
* Correspondence: khoh@snu.ac.kr

${ }^{8}$ Division of Nephrology, Department of Internal Medicine, Seoul National University College of Medicine, 101 Daehak-ro, Chong No Gu, 03080 Seoul, Korea

Full list of author information is available at the end of the article
}

such as endothelial dysfunction, hyperphosphatemia, vascular calcifications, and chronic inflammation play important roles in the advancement of the disease [2]. Vascular calcification is a common complication in CKD, resulting from altered mineral homeostasis and an imbalance of calcification promoters and inhibitors [3, 4]. The extent and anatomic type of calcification are well-known predictors of vascular mortality [5].

Coronary artery calcification is significantly associated with the occurrence of major cardiovascular events. As measured by multi-detector computed tomography, the degree of calcification is one of the most widely accepted

(C) The Author(s). 2021 Open Access This article is licensed under a Creative Commons Attribution 4.0 International License, which permits use, sharing, adaptation, distribution and reproduction in any medium or format, as long as you give appropriate credit to the original author(s) and the source, provide a link to the Creative Commons licence, and indicate if changes were made. The images or other third party material in this article are included in the article's Creative Commons licence, unless indicated otherwise in a credit line to the material. If material is not included in the article's Creative Commons licence and your intended use is not permitted by statutory regulation or exceeds the permitted use, you will need to obtain permission directly from the copyright holder. To view a copy of this licence, visit http://creativecommons.org/licenses/by/4.0/ The Creative Commons Public Domain Dedication waiver (http://creativecommons.org/publicdomain/zero/1.0/) applies to the data made available in this article, unless otherwise stated in a credit line to the data. 
tools for detecting coronary atherosclerosis and estimating coronary risk assessment with high sensitivity and specificity [6]. This tool is valid not only in asymptomatic adults [7, 8] but also in the CKD population [9]. Therefore, the coronary artery calcium (CAC) score is now used to assess cardiovascular risk in patients with CKD.

Uric acid (UA), the end product of purine catabolism, has been in the spotlight for decades as a risk factor for cardiovascular disease. Many epidemiologic studies have revealed that hyperuricemia is associated with an increased risk of coronary heart disease [10], heart failure [11], and fatal arrhythmias [12]. UA showed a positive association with $\mathrm{CAC}$ in health screening for the general population [13-16] and elevated UA could predict the development of coronary artery calcification progression [17]. However, few studies have investigated the relationship between UA and CAC in the CKD population. Therefore, in this study, we sought to demonstrate whether serum UA level is associated with CAC in the predialysis CKD population.

\section{Methods}

\section{Study design and population}

This was a cross-sectional study designed to assess the association between serum UA and CAC in patients with CKD. The study population consisted of participants in the KoreaN Cohort Study for Outcome in Patients With Chronic Kidney Disease (KNOW-CKD), a nationwide prospective cohort study, including CKD stage 1 to 5 nondialysis patients, that was designed to clarify the natural course and complication profiles of CKD. Details of the KNOW-CKD study's rationale and design have been described previously [18] and the baseline characteristics of the study population were previously published [19]. A total of 2,238 subjects were initially screened. After excluding 126 participants who had not performed coronary artery computed tomography, 434 participants who had taken UA lowering medication, and 328 participants with missing information in any one of the variables included in the study, 1350 participants were analysed.

\section{Data collection}

Baseline demographics and laboratory data were retrieved from the electronic data management system (PhactaX, Seoul, Republic of Korea) with assistance from the Division of Data Management at Seoul National University Medical Research Collaborating Center. Socio-demographic characteristics, smoking history, medication, and comorbidities were collected at the time of enrollment. Anthropometric indexes including height, weight, waist circumference, hip circumference, and resting blood pressure (BP) were measured in the clinic.
Laboratory data were analysed at the hospital laboratory of each participating centre. Serum samples were collected and sent to the central laboratory (Lab Genomics, Seoul, Republic of Korea) to measure creatinine levels. The estimated glomerular filtration rate (eGFR) was calculated through the CKD-EPI equation [20].

CAC score was evaluated at each research institution by an electron-beam computed tomography (CT) scanner or a multi-detector CT. Specifically, SOMATOM Definition Flash (Siemens Healthineers), SOMATOM Force (Siemens Healthineers), Revolution CT (GE healthcare), Discovery CT750 HD (GE Healthcare), Brilliance iCT 256 slice (Philips Medical Systems), Brilliance 64 CT scanner (Philips Medical Systems), IQon Spectral CT (Philips Medical Systems) were used. The quantitative CAC score was assessed using the Agatston score [21]; If a lesion with a density of 130 Hounsfield unit (less than $\mathrm{HU}$ ) and a width of $1 \mathrm{~mm}^{2}$ or more is in the coronary artery position, it is determined as positive. In each lesion, 1 point for 130 to $199 \mathrm{HU}, 2$ for 200 to 299 HU Points, 3 points for $300 \sim 399$ HU, 4 points for 400 or more, were measured as the sum of these values.

\section{Statistical analysis}

Continuous variables were expressed as mean \pm standard deviation, and categorical variables were expressed as numbers and proportions. The comparisons were made using the independent $\mathrm{t}$-test or analysis of variance for continuous variables and the chi-squared test for categorical variables. A $P$-value $<0.05$ was considered statistically significant. The adjusted odds ratios of CAC $>0$ associated with risk factors were estimated using logistic regression analysis. Only covariates that were significant $(p<0.05)$ were retained in the multivariable analysis. The independent association between UA and CAC was also evaluated using restricted cubic splines. To visualise the association of UA and CAC, selected knots automatically, cubic splines were drawn by the "gam," "mgcv" packages in R. Statistical analysis was performed using $\mathrm{R}$ software (version 3.2.2).

\section{Ethics statement}

This study was conducted in accordance with the Declaration of Helsinki. The study protocol was approved by the institutional review board at each participating hospital, including Seoul National University Hospital (1104-089-359), Seoul National University Bundang Hospital (B-1106/129-008), Yonsei University Severance Hospital (4-2011-0163), Kangbuk Samsung Medical Center (2011-01-076), Seoul St. Mary's Hospital (KC11OIMI0441), Gil Hospital (GIRBA2553), Eulji General Hospital (201105-01), Chonnam National University Hospital (CNUH-2011-092), and Pusan Paik Hospital 
(11-091). All participants provided written informed consent.

\section{Results}

\section{Clinical characteristics of participants with CAC}

The mean age was $53.5 \pm 11.9$ years, and 758 (56.2\%) were men. Seventy $(5.2 \%)$ had a history of coronary artery disease, 499 (37.0\%) had diabetes mellitus, and 1286 (95.3\%) had hypertension. The mean eGFR was $56.7 \pm 32.4 \mathrm{ml} / \mathrm{min} / 1.73 \mathrm{~m}^{2}$, and the serum UA level was $7.0 \pm 1.9 \mathrm{mg} / \mathrm{dL}$. Of these, $645(47.8 \%)$ belonged to CACS 0 and 705 (52.2\%) belonged to CACS $>0$. Table 1 shows the clinical characteristics of CAC 0 and $C A C>0$. Compared to those with CAC 0, participants with $C A C>0$ were older and had a higher proportion of males. Comorbidities, such as coronary artery disease, diabetes mellitus, and hypertension, were higher in $\mathrm{CAC}>0$, and the proportion of current smokers and lipid-lowering medications was also higher. The UA, phosphate, PTH, and 24-hour urine protein levels were significantly higher in participants with $C A C>0$. In contrast, the levels of eGFR, calcium, LDL-cholesterol, and HDL-cholesterol were significantly lower in $\mathrm{CAC}>0$.

We further divided as CAC $0,>0-100,>100-400$, > 400. The participants with high CAC score were older and had higher proportion of male, coronary artery disease, diabetes mellitus and hypertension. The level of
eGFR, calcium, LDL cholesterol, and HDL cholesterol were lower, whereas uric acid, phosphate, PTH, and $24 \mathrm{~h}$ urine protein were higher according to higher CAC level (Supplementary Table 1).

\section{Association factors with CAC}

Table 2 lists several factors associated with $C A C>0$. The age- and sex-adjusted logistic regression analysis revealed UA (Odds ratio (OR) 1.11, $95 \%$ confidence interval (CI) 1.04-1.19, $P=0.003$ ) was significantly associated with having $\mathrm{CAC}>0$. However, on multivariate logistic regression analysis, adjusted for age, sex, coronary artery disease, diabetes mellitus, use of lipid-lowering agents, mean BP, waist-hip ratio, eGFR, calcium, phosphate, LDL-cholesterol, HDL-cholesterol, PTH, and 24-hour urine protein, UA showed no association with CAC $>0$ (OR 1.00, $95 \%$ CI $0.91-1.09, P=0.953$ ). History of coronary artery disease, history of diabetes mellitus, use of lipid-lowering agents, mean BP, and phosphate levels were positively associated with $\mathrm{CAC}$ in multivariate analysis.

We further divided the participants by eGFR $\geq 60,30$ 59 , and $<30 \mathrm{ml} / \mathrm{min} / 1.73 \mathrm{~m}^{2}$. UA level showed a positive association with CAC $>0$ (OR 1.23, $95 \%$ CI 1.02-1.49, $P=0.036)$ only in estimated GFR $>60 \mathrm{ml} / \mathrm{min} / 1.73 \mathrm{~m}^{2}$ (Table 3). UA had no association with CACS in eGFR $30-59 \mathrm{ml} / \mathrm{min} / 1.73 \mathrm{~m}^{2}$ (OR 0.92, $95 \%$ CI $0.78-1.08, P=$ 0.309 ) or $30 \mathrm{ml} / \mathrm{min} / 1.73 \mathrm{~m}^{2}$ (OR 0.92, $95 \%$ CI 0.79

Table 1 Clinical characteristics of participants

\begin{tabular}{|c|c|c|c|c|}
\hline & Total $(n=1350)$ & CAC $0(n=645)$ & CAC $>0 \quad(n=705)$ & $P$ value \\
\hline Age, year & $53.5 \pm 11.9$ & $47.6 \pm 11.3$ & $58.8 \pm 9.8$ & $<0.0001$ \\
\hline Sex, male (\%) & $758(56.2)$ & $277(43.0)$ & $481(68.2)$ & $<0.0001$ \\
\hline Coronary artery disease (\%) & $70(5.2)$ & $2(0.3)$ & $68(9.7)$ & $<0.0001$ \\
\hline Diabetes mellitus (\%) & $499(37.0)$ & $97(15.0)$ & $402(57.0)$ & $<0.0001$ \\
\hline Hypertension (\%) & $1286(95.3)$ & $593(91.9)$ & $693(98.3)$ & $<0.0001$ \\
\hline current smoker (\%) & $217(16.1)$ & 88 (13.6) & $129(18.3)$ & 0.020 \\
\hline Use of lipid-lowering drugs (\%) & $727(53.9)$ & $279(43.3)$ & $448(63.6)$ & $<0.0001$ \\
\hline Mean blood pressure, $\mathrm{mmHg}$ & $94.0 \pm 11.6$ & $93.1 \pm 11.3$ & $94.8 \pm 11.9$ & 0.005 \\
\hline Waist hip ratio (\%) & $89.8 \pm 7.2$ & $87.6 \pm 7.8$ & $91.8 \pm 5.8$ & $<0.0001$ \\
\hline Creatinine, mg/dL & $1.72 \pm 1.12$ & $1.44 \pm 0.93$ & $1.98 \pm 1.21$ & $<0.0001$ \\
\hline $\mathrm{eGFR}, \mathrm{ml} / \mathrm{min} / 1.73 \mathrm{~m}^{2}$ & $56.7 \pm 32.4$ & $67.3 \pm 33.9$ & $47.1 \pm 27.5$ & $<0.0001$ \\
\hline Uric acid, mg/dL & $7.0 \pm 1.9$ & $6.7 \pm 2.0$ & $7.3 \pm 1.9$ & $<0.0001$ \\
\hline Calcium, mg/dL & $9.1 \pm 0.5$ & $9.2 \pm 0.49$ & $9.1 \pm 0.6$ & $<0.0001$ \\
\hline Phosphate, mg/dL & $3.7 \pm 0.7$ & $3.6 \pm 0.6$ & $3.8 \pm 0.7$ & $<0.0001$ \\
\hline LDL cholesterol, mmol/L & $98.4 \pm 31.9$ & $102.6 \pm 29.9$ & $94.5 \pm 33.1$ & $<0.0001$ \\
\hline HDL cholesterol, mmol/L & $50.0 \pm 15.8$ & $53.6 \pm 15.5$ & $46.8 \pm 15.4$ & $<0.0001$ \\
\hline Ln PTH, pg/mL & $3.95 \pm 0.74$ & $3.85 \pm 0.70$ & $4.05 \pm 0.77$ & $<0.0001$ \\
\hline Ln 24 h urine protein, mg & $6.1 \pm 1.8$ & $5.7 \pm 1.9$ & $6.5 \pm 1.6$ & $<0.0001$ \\
\hline
\end{tabular}

eGFR estimated glomerular filtration rate, $L D L$ low density lipoprotein, $H D L$ high density lipoprotein, $P T H$ parathyroid hormone 
Table 2 Multivariate-adjusted odds ratios of CAC $>0$ associated with several risk factors

\begin{tabular}{|c|c|c|c|c|}
\hline & \multicolumn{2}{|c|}{ age-, sex- adjusted OR } & \multicolumn{2}{|c|}{ Multivariate-Adjusted OR } \\
\hline & OR (95\% CI) & $p$-value & OR $(95 \% \mathrm{Cl})$ & $p$-value \\
\hline Current smoker & $1.29(0.90,1.85)$ & 0.169 & - & - \\
\hline Coronary artery disease & $23.0(5.3,100.6)$ & $<.0001$ & $10.44(2.45,44.48)$ & 0.002 \\
\hline Hypertension & $2.04(0.98,4.24)$ & 0.057 & - & - \\
\hline Diabetes mellitus & $5.12(3.83,6.86)$ & $<.0001$ & $3.53(2.56,4.87)$ & $<.0001$ \\
\hline Use of lipid-lowering drugs & $1.66(1.29,2.14)$ & $<.0001$ & $1.37(1.02,1.84)$ & 0.039 \\
\hline Mean blood pressure & $1.02(1.01,1.03)$ & $<.0001$ & $1.02(1.01 .1 .03)$ & 0.006 \\
\hline Waist hip ratio & $1.05(1.03,1.07)$ & $<.0001$ & $1.02(1.00,1.05)$ & 0.075 \\
\hline eGFR & $0.99(0.98,0.99)$ & $<.0001$ & $1.00(0.99,1.01)$ & 0.591 \\
\hline Uric acid & $1.11(1.04,1.19)$ & 0.003 & $1.00(0.91,1.09)$ & 0.953 \\
\hline Calcium & $0.64(0.50,0.81)$ & $<.0001$ & $0.83(0.61,1.11)$ & 0.206 \\
\hline Phosphate & $1.82(1.47,2.24)$ & $<.0001$ & $1.31(1.02,1.68)$ & 0.032 \\
\hline LDL cholesterol & $1.00(0.99,1.00)$ & 0.038 & $1.00(1.00,1.00)$ & 0.775 \\
\hline HDL cholesterol & $0.98(0.97,0.99)$ & $<.0001$ & $0.99(0.98,1.00)$ & 0.171 \\
\hline Ln PTH & $1.49(1.25,1.78)$ & $<.0001$ & $1.03(0.81 .1 .32)$ & 0.793 \\
\hline Ln 24hour urine protein & $1.24(1.14,1.34)$ & $<.0001$ & $0.99(0.90,1.10)$ & 0.909 \\
\hline
\end{tabular}

eGFR estimated glomerular filtration rate, $L D L$ low density lipoprotein, $H D L$ high density lipoprotein, $P T H$ parathyroid hormone

1.08, $P=0.426)$. Restricted cubic splines of UA on the CAC $>0$, stratified by eGFR, showed that CAC increased steadily with higher UA levels only in estimated GFR > $60 \mathrm{ml} / \mathrm{min} / 1.73 \mathrm{~m}^{2}$ (Fig. 1).

\section{Discussion}

In the present study, we showed that over half of the CKD population had CAC. The patients with $\mathrm{CAC}>0$ had higher UA levels than those with CAC 0 , and UA showed a positive relationship with $C A C>0$ in age- and sex-adjusted logistic regression analysis. However, UA showed an association with $\mathrm{CAC}>0$ in multivariateadjusted logistic regression analysis only in the early stage of CKD, and this association disappeared in advanced CKD.

Table 3 Multivariate-adjusted odds ratios (95\% Confidence Intervals) for CAC > 0 associated with serum uric acid according to CKD stages

\begin{tabular}{llll}
\hline & $\mathbf{n}$ & OR $(\mathbf{9 5} \% \mathbf{C l})$ & $\boldsymbol{p}$-value \\
\hline eGFR $\geq 60 \mathrm{ml} / \mathrm{min} / 1.73 \mathrm{~m}^{2}$ & 541 & & \\
Uric acid & & $1.23(1.02,1.49)$ & 0.036 \\
eGFR $30-59 \mathrm{ml} / \mathrm{min} / 1.73 \mathrm{~m}^{2}$ & 475 & & \\
Uric acid & & $0.92(0.78,1.08)$ & 0.309 \\
eGFR $<30 \mathrm{ml} / \mathrm{min} / 1.73 \mathrm{~m}^{2}$ & 334 & & \\
Uric acid & & $0.92(0.79,1.08)$ & 0.426 \\
\hline
\end{tabular}

CKD chronic kidney disease
UA, formerly considered a significant antioxidant in humans, has been regarded as a risk factor for cardiovascular disease in the past two decades. Previous studies have shown that elevated UA levels could predict the severity and morphology of coronary atherosclerosis [16] and elevated UA is associated with greater lipid content of coronary plaque in patients with acute coronary syndrome [22]. In line with this, hyperuricemia showed a positive association with CAC in the general population in previous studies $[13,15]$. Several experimental studies have demonstrated the mechanism of UA in atherosclerosis. In endothelial cells, UA decreases nitric oxide bioavailability and inhibits cell migration and proliferation $[23,24]$. UA significantly increased the production of reactive oxygen species, facilitated the activation of the renin-angiotensin system [25], and induced endothelial dysfunction. In addition, UA has been shown to have pro-inflammatory activity. UA triggers the expression of pro-inflammatory cytokines such as C-reactive protein [26, 27], contributing to atherosclerosis.

However, UA failed to show an association with CAC in patients with CKD, not only in this study population but also in another CKD cohort [28]. The authors believe that this is due to the complex process of vascular calcification in CKD. Vascular calcification can occur in two areas of the vessel wall: the intima and the media. Intima calcification is associated with atherosclerosis, whereas calcification in the media is associated with 


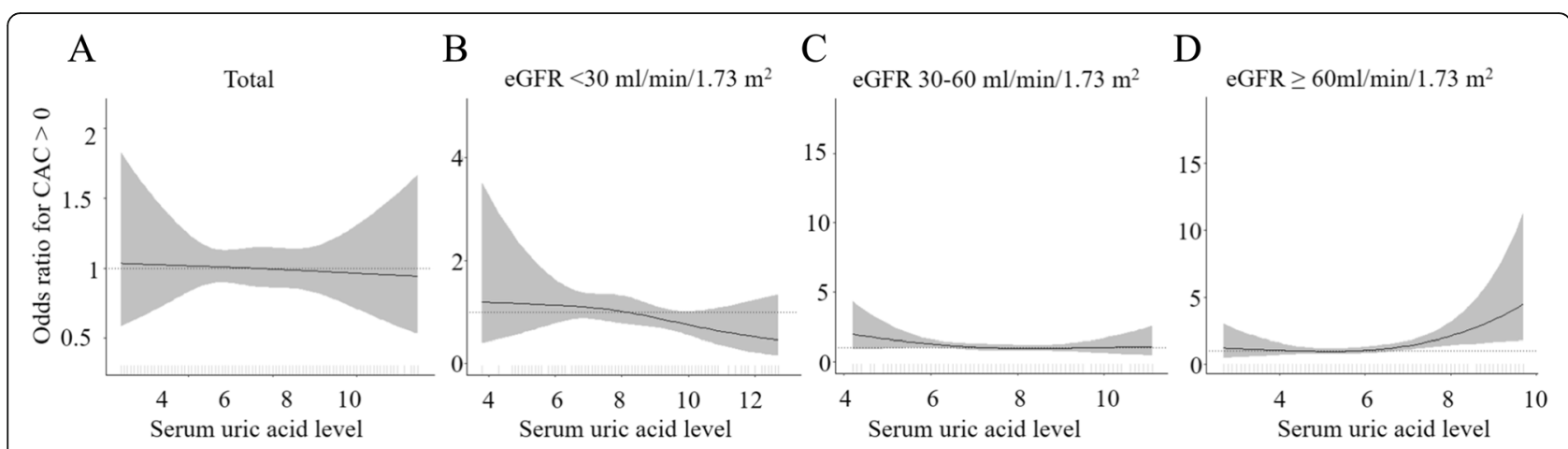

Fig. 1 Restricted cubic splines of serum uric acid on the coronary artery calcium score $>0$, stratified by CKD stage. A total, B eGFR $<30 \mathrm{ml} / \mathrm{min} /$ $1.73 \mathrm{~m}^{2}$, C eGFR $30-59 \mathrm{ml} / \mathrm{min} / 1.73 \mathrm{~m}, \mathbf{D}$ eGFR $\geq 60 \mathrm{ml} / \mathrm{min} / 1.73 \mathrm{~m}^{2}$

advanced age, diabetes, and CKD [29]. Abnormal calcium and phosphate levels and parathyroid hormone levels in kidney disease contribute to the phenotype switch of vascular smooth muscle cells to osteoblastlike cells and local inflammation, contributing to vascular calcification [4].

Unlike UA, phosphate showed a positive association with CAC throughout the whole stage of CKD in this study. Phosphate is an integral component of hydroxyapatite, the calcium mineral seen in bone and vascular calcification. It is also a part of the signalling cascade that triggers vascular calcification [29]. Calcification of the coronary arteries is independently associated with hyperphosphatemia in patients with end-stage renal disease, and elevated phosphate levels, even those in the high-normal range, are correlated with a higher risk of myocardial infarction and mortality in patients with CKD [30].

This study has some limitations. This is a crosssectional study; therefore, we could not identify a longitudinal relationship between UA and CAC. Moreover, this study could not confirm that UA is associated with cardiovascular events in patients with CKD. CAC is a complex process; therefore, there could be confounders that we could not consider. However, this study is the first, to the best of our knowledge, to elucidate that UA showed a different relationship with CAC according to CKD stages.

\section{Conclusions}

The UA level was significantly associated with CAC in early CKD but not in advanced CKD. Longitudinal studies are required to confirm the association between UA and CAC and the effect of UA lowering therapy for $\mathrm{CAC}$ in patients with CKD.

\section{Abbreviations}

CVD: Cardiovascular disease; CKD: Chronic kidney disease; CAC: Coronary artery calcification; UA: Uric acid; KNOW-CKD: KoreaN Cohort Study for Outcome in Patients With Chronic Kidney Disease; BP: Blood pressure;
eGFR: Estimated glomerular filtration rate; OR: Odds ratio; Cl: Confidence interval

\section{Supplementary Information}

The online version contains supplementary material available at https://doi. org/10.1186/s12882-021-02463-2.

Additional file 1: Supplementary table 1. Baseline characteristics of participants according to CAC $0,>0-100,>100-400,>400$.

\section{Acknowledgements}

Not applicable.

\section{Authors' contributions}

Study concept and design: M.H. and H.K, Acquisition of data: YS.K. and KH.C. Data analysis: HJ.K and E.K., Review the results and interpreted the data: SW.K and C.A., Writing the manuscript:M.H., Review and revised the manuscript: KH.O. All authors have read and approved the manuscript.

\section{Funding}

This study was supported by the Research Program funded by the Korea Center for Disease Control and Prevention (2011E3300300, 2012E3301100, 2013Е3301600, 2013Е3301601, 2013Е3301602, 2016Е3300200, 2016Е3300201, 2016E3300202, 2019E320100, 2019E320101, and 2019E320102).

Availability of data and materials

The datasets used and analysed during the current study available from the corresponding author on reasonable request.

\section{Declarations}

\section{Ethics approval and consent to participate}

This study was conducted in accordance with the Declaration of Helsinki. The study protocol was approved by the institutional review board at each participating hospital, including Seoul National University Hospital (1104-089359), Seoul National University Bundang Hospital (B-1106/129-008), Yonsei University Severance Hospital (4-2011-0163), Kangbuk Samsung Medical Center (2011-01-076), Seoul St. Mary's Hospital (KC11OIMI0441), Gil Hospital (GIRBA2553), Eulji General Hospital (201105-01), Chonnam National University Hospital (CNUH-2011-092), and Pusan Paik Hospital (11-091). All participants provided written informed consent.

Consent for publication

Not applicable.

Competing interests

The authors have nothing to disclose. 


\section{Author details}

${ }^{1}$ Department of Internal Medicine, Hallym University Hangang Sacred Heart Hospital, Seoul, Korea. ${ }^{2}$ Department of Internal Medicine, Hallym University Chuncheon Sacred Heart Hospital, Chuncheon, Korea. ${ }^{3}$ Department of Internal Medicine, Pusan National University Hospital, Busan, Korea. ${ }^{4}$ Department of Internal Medicine, Ewha Womans University Seoul Hospital, Ewha Womans University College of Medicine, Seoul, Korea. ${ }^{5}$ Department of Internal Medicine, The Catholic University of Korea, Seoul St. Mary's Hospital, Seoul, Korea. ${ }^{6}$ Department of Internal Medicine, College of Medicine, Institute of Kidney Disease Research, Yonsei University, Seoul, Republic of Korea. ${ }^{7}$ Department of Internal Medicine, Chonnam National University Medical School, Gwangju, Korea. ${ }^{8}$ Division of Nephrology, Department of Internal Medicine, Seoul National University College of Medicine, 101 Daehak-ro, Chong No Gu, 03080 Seoul, Korea.

Received: 8 February 2021 Accepted: 19 June 2021

Published online: 04 July 2021

\section{References}

1. Axelsson Raja A, Warming PE, Nielsen TL, Plesner LL, Ersboll M, Dalsgaard M, Schou M, Rydahl C, Brandi L, Iversen K. Left-sided heart disease and risk of death in patients with end-stage kidney disease receiving haemodialysis: an observational study. BMC Nephrol. 2020;21(1):413.

2. Subbiah AK, Chhabra YK, Mahajan S. Cardiovascular disease in patients with chronic kidney disease: a neglected subgroup. Heart Asia. 2016;8(2):56-61.

3. Lee SM, Kim SE, Lee JY, Jeong HJ, Son YK, An WS. Serum myostatin levels are associated with abdominal aortic calcification in dialysis patients. Kidney Res Clin Pract. 2019;38(4):481-9.

4. Schlieper G, Schurgers L, Brandenburg V, Reutelingsperger C, Floege J. Vascular calcification in chronic kidney disease: an update. Nephrol Dial Transplant. 2016;31(1):31-9.

5. Mizobuchi M, Towler D, Slatopolsky E. Vascular calcification: the killer of patients with chronic kidney disease. J Am Soc Nephrol. 2009;20(7):1453-64

6. Neves PO, Andrade J, Moncao H. Coronary artery calcium score: current status. Radiol Bras. 2017:50(3):182-9.

7. Taylor AJ, Bindeman J, Feuerstein I, Cao F, Brazaitis M, O'Malley PG. Coronary calcium independently predicts incident premature coronary heart disease over measured cardiovascular risk factors: mean three-year outcomes in the Prospective Army Coronary Calcium (PACC) project. J Am Coll Cardiol. 2005; 46(5):807-14.

8. Greenland P, LaBree L, Azen SP, Doherty TM, Detrano RC. Coronary artery calcium score combined with Framingham score for risk prediction in asymptomatic individuals. JAMA. 2004;291(2):210-5.

9. Chen J, Budoff MJ, Reilly MP, Yang W, Rosas SE, Rahman M, Zhang X, Roy JA, Lustigova E, Nessel L, et al. Coronary Artery Calcification and Risk of Cardiovascular Disease and Death Among Patients With Chronic Kidney Disease. JAMA Cardiol. 2017;2(6):635-43

10. Kim SY, Guevara JP, Kim KM, Choi HK, Heitjan DF, Albert DA. Hyperuricemia and coronary heart disease: a systematic review and meta-analysis. Arthritis Care Res (Hoboken). 2010;62(2):170-80.

11. Huang H, Huang B, Li Y, Huang Y, Li J, Yao H, Jing X, Chen J, Wang J. Uric acid and risk of heart failure: a systematic review and meta-analysis. Eur J Heart Fail. 2014;16(1):15-24.

12. Yamada S, Suzuki H, Kamioka M, Kamiyama Y, Saitoh S, Takeishi Y. Uric acid increases the incidence of ventricular arrhythmia in patients with left ventricular hypertrophy. Fukushima J Med Sci. 2012;58(2):101-6.

13. Kim H, Kim SH, Choi AR, Kim S, Choi HY, Kim HJ, Park HC. Asymptomatic hyperuricemia is independently associated with coronary artery calcification in the absence of overt coronary artery disease: a single-center crosssectional study. Medicine (Baltimore). 2017;96(14):e6565.

14. Grossman C, Shemesh J, Koren-Morag N, Bornstein G, Ben-Zvi I, Grossman E. Serum uric acid is associated with coronary artery calcification. J Clin Hypertens (Greenwich). 2014;16(6):424-8.

15. Krishnan E, Pandya BJ, Chung L, Dabbous O. Hyperuricemia and the risk for subclinical coronary atherosclerosis-data from a prospective observational cohort study. Arthritis Res Ther. 2011;13(2):R66

16. Kaya EB, Yorgun $H$, Canpolat U, Hazirolan $T$, Sunman $H$, Ulgen A, Ates AH, Aytemir K, Tokgozoglu L, Kabakci G, et al. Serum uric acid levels predict the severity and morphology of coronary atherosclerosis detected by multidetector computed tomography. Atherosclerosis. 2010;213(1):178-83.
17. Jun JE, Lee YB, Lee SE, Ahn JY, Kim G, Jin SM, Hur KY, Lee MK, Kang MR, Kim $\mathrm{JH}$. Elevated serum uric acid predicts the development of moderate coronary artery calcification independent of conventional cardiovascular risk factors. Atherosclerosis. 2018:272:233-9.

18. Oh KH, Park SK, Park HC, Chin HJ, Chae DW, Choi KH, Han SH, Yoo TH, Lee K, Kim YS, et al. KNOW-CKD (KoreaN cohort study for Outcome in patients With Chronic Kidney Disease): design and methods. BMC Nephrol. 2014;15: 80.

19. Kang E, Han M, Kim H, Park SK, Lee J, Hyun YY, Kim YS, Chung W, Kim HJ, Oh YK, et al. Baseline General Characteristics of the Korean Chronic Kidney Disease: Report from the KoreaN Cohort Study for Outcomes in Patients With Chronic Kidney Disease (KNOW-CKD). J Korean Med Sci. 2017;32(2): 221-30.

20. Levey AS, Stevens LA, Schmid CH, Zhang YL, Castro AF 3, Feldman HI, Kusek JW, Eggers $P$, Van Lente F, Greene T, et al. A new equation to estimate glomerular filtration rate. Ann Intern Med. 2009;150(9):604-12.

21. Agatston AS, Janowitz WR, Hildner FJ, Zusmer NR, Viamonte M Jr., Detrano R. Quantification of coronary artery calcium using ultrafast computed tomography. J Am Coll Cardiol. 1990;15(4):827-32.

22. Saito Y, Nakayama T, Sugimoto K, Fujimoto Y, Kobayashi Y. Relation of Lipid Content of Coronary Plaque to Level of Serum Uric Acid. Am J Cardiol. 2015:116(9):1346-50.

23. Khosla UM, Zharikov S, Finch JL, Nakagawa T, Roncal C, Mu W, Krotova K, Block ER, Prabhakar S, Johnson RJ. Hyperuricemia induces endothelial dysfunction. Kidney Int. 2005;67(5):1739-42.

24. Gersch C, Palii SP, Kim KM, Angerhofer A, Johnson RJ, Henderson GN. Inactivation of nitric oxide by uric acid. Nucleosides Nucleotides Nucleic Acids. 2008;27(8):967-78.

25. Yu MA, Sanchez-Lozada LG, Johnson RJ, Kang DH. Oxidative stress with an activation of the renin-angiotensin system in human vascular endothelial cells as a novel mechanism of uric acid-induced endothelial dysfunction. J Hypertens. 2010;28(6):1234-42.

26. Johnson RJ, Rodriguez-Iturbe B, Kang DH, Feig DI, Herrera-Acosta J. A unifying pathway for essential hypertension. Am J Hypertens. 2005;18(3): 431-40.

27. Kang DH, Park SK, Lee IK, Johnson RJ. Uric acid-induced C-reactive protein expression: implication on cell proliferation and nitric oxide production of human vascular cells. J Am Soc Nephrol. 2005;16(12):3553-62.

28. Bundy JD, Chen J, Yang W, Budoff M, Go AS, Grunwald JE, Kallem RR, Post WS, Reilly MP, Ricardo AC, et al. Risk factors for progression of coronary artery calcification in patients with chronic kidney disease: the CRIC study. Atherosclerosis. 2018;271:53-60.

29. Paloian NJ, Giachelli CM. A current understanding of vascular calcification in CKD. Am J Physiol Renal Physiol. 2014;307(8):F891-900.

30. Kestenbaum B, Sampson JN, Rudser KD, Patterson DJ, Seliger SL, Young B, Sherrard DJ, Andress DL. Serum phosphate levels and mortality risk among people with chronic kidney disease. J Am Soc Nephrol. 2005;16(2):520-8.

\section{Publisher's Note}

Springer Nature remains neutral with regard to jurisdictional claims in published maps and institutional affiliations.

Ready to submit your research? Choose BMC and benefit from:

- fast, convenient online submission

- thorough peer review by experienced researchers in your field

- rapid publication on acceptance

- support for research data, including large and complex data types

- gold Open Access which fosters wider collaboration and increased citations

- maximum visibility for your research: over $100 \mathrm{M}$ website views per year

At $\mathrm{BMC}$, research is always in progress.

Learn more biomedcentral.com/submission 